\title{
FINANCIAMENTO E EXPANSÃO DO ENSINO MÉDIO: O CASO DA DIVERSIFICAÇÃO DA OFERTA NO CEARÁ
}

\author{
FINANCING AND EXPANSION OF HIGH SCHOOL: THE CASE OF OFFER \\ DIVERSIFICATION IN CEARÁ
}

\author{
Sofia Lerche Vieira \\ Doutora em Educação \\ Professora titular da Universidade Estadual do Ceará \\ sofia.lerche@uece.br \\ Eloisa Maia Vidal \\ Doutora em Educação \\ Professora associada da Universidade Estadual do Ceará \\ eloisamvidal@yahoo.com.br \\ Paulo Alexandre Sousa Queiroz \\ Mestre em Educação \\ pauloalexandre1000@gmail.com
}

Coordenador da $7^{\circ}$ Coordenadoria Regional de Desenvolvimento da Educação do Estado do Ceará

Resumo: O artigo tem como objetivo discutir o financiamento da educação básica identificando seus nexos com a expansão e a diversificação da oferta de ensino médio nos últimos quarenta anos, tomando o Ceará como exemplo. Utiliza a metodologia de natureza explicativa, com uso de fontes de informações históricas, envolvendo dados quantitativos, documentos oficiais e fontes secundárias de autores com produção sobre o assunto. Os resultados mostram que, até 2007, ano de criação do Fundeb, se observa um descompasso entre as condições de financiamento e a expansão das matrículas e que o ensino médio, nesse período, dependia apenas de recursos do tesouro estadual ou dos programas federais específicos e intercorrentes. A partir de 2005, começa a ocorrer estabilidade de matrículas e se inicia a diversificação da oferta, incluindo educação profissional e a de tempo integral, favorecida pelas condições de financiamento e pelo incentivo do Governo Federal, com programas e projetos dirigidos essas ofertas. No Ceará, um conjunto de iniciativas relacionadas à diversificação da oferta de ensino médio criou quatro tipos de escolas no interior da rede estadual, que, embora convivam em relativa harmonia, apresentam diferentes condições de acesso e de permanência dos alunos, revelando situações de iniquidades agudas no que se refere ao direito à educação.

Palavras chaves: política educacional; financiamento; ensino médio; expansão; Ceará.

Abstract: The peper aims to discuss the financing of basic education identifying its links with the expansion and the diversification of secondary education supply in the last forty years, taking Ceará as an example. It uses explanatory nature methodology, using historical information sources, involving quantitative data, official documents and secondary sources of authors with production on the matter. The results show that, until 2007, the year Fundeb was created, there was a mismatch between financing conditions and enrollment expansion, and that secondary education, in this period, depended only on State Treasure resources or specific and intercurrent federal programs. From 2005 onwards, stability of enrollments began to occur and the offer began to be diversified, including professional and full time education, favored by financing conditions and federal government incentives, with programs and projects aimed at these offers. In Ceará, a set of initiatives related to diversifying the supply of secondary education created four types of schools within the state network, which, although coexist in relative harmony, have different conditions of access and permanence of students, revealing situations of acute inequities in terms of be refers to the right to education.

Keywords: educational policy; financing; high school; expansión; Ceará.

Para citar - (ABNT NBR 6023:2018)

VIEIRA, Sofia Lerche; VIDAL, Eloisa Maia; QUEIROZ, Paulo Alexandre Sousa. Financiamento e expansão do ensino médio: o caso da diversificação da oferta no Ceará. Eccos - Revista Científica, São Paulo, n. 58, p. 1-23, e20852, jul./set. 2021. Disponível em: https://doi.org/10.5585/eccos.n58.20852. 


\section{Introdução}

O financiamento da educação é um tema-chave do debate sobre política educacional no Brasil. Longe de constituir-se em questão esgotada pela literatura no campo, representa desafio fecundo e permanente à reflexão. Seus movimentos possuem estreita articulação com circunstâncias que ultrapassam o âmbito educacional propriamente dito reportando-se a contextos políticos, econômicos e sociais que vão se firmando ao longo da história. Por isso mesmo, oscilam conforme ciclos de maior ou menor capacidade de operacionalização das políticas públicas.

Este texto pretende analisar questões relativas à maior ou menor presença de capacidade financeira para fazer face ao desafio de crescimento da oferta de ensino médio que vai se colocando em cena, à medida em que a universalização do ensino fundamental se impõe à política educacional brasileira. A análise identifica, no fenômeno da expansão, um fio condutor para compreender a complexa realidade onde se inscreve o tema em questão. Toma-se o caso do Ceará como ilustração, na medida em que se oferecem elementos fecundos para uma compreensão dos nexos entre o financiamento e a expansão.

Em se tratando de um país de organização federativa, a União, os Estados e os Municípios possuem atribuições e responsabilidades diferenciadas. Enquanto à primeira cabe a coordenação da política nacional da educação (LDB, Art. $8^{0} \S^{0}$ ) e o exercício de função supletiva e redistributiva (LDB, Art. $9^{0}$, III), a estados e municípios compete a oferta dos serviços de educação básica, mais especificamente a educação infantil (responsabilidade municipal - LDB, Art. 11, V), o ensino fundamental (responsabilidade municipal e estadual LDB, Art. 10, II e VI)) e o ensino médio (responsabilidade estadual - LDB, Art. 10, VI). Considerando tais circunstâncias de governança, estados e municípios adotam políticas próprias para o enfrentamento de seus desafios, sendo oportuno conhecer as dinâmicas específicas das diferentes unidades federadas. $\mathrm{O}$ estudo do caso do ensino médio cearense, nesse sentido, representa uma alternativa para o conhecimento do tema em foco.

É oportuno situar historicamente a questão. No início dos anos 2000, o ensino médio cearense, em sintonia com uma tendência nacional, atravessou um surto expansionista sem precedentes. Após um período de crescimento de matrículas, estas vieram a se estabilizar e, posteriormente, a decrescer. Atendendo à determinação constitucional (EC no 59/2009) de ampliação da escolaridade obrigatória, de sete a quatorze anos para quatro a dezessete anos de idade, como no resto do país, o ensino médio do referido estado passa a abrigar segmentos cada vez mais significativos da população na faixa etária correspondente a esta etapa de escolaridade. 
A análise a ser desenvolvida no percurso da reflexão irá deter-se sobre pormenores deste processo.

Elegendo a oferta de ensino médio no Ceará como foco, o artigo aborda o financiamento, a expansão de matrículas e a diversificação da oferta, buscando identificar articulações mútuas entre os mesmos. Se o aumento de matrículas começa a se esboçar já no final dos anos noventa, as condições para o financiamento desta expansão vão se colocar muito mais tarde, sob a égide da aprovação do Fundo de Manutenção e Desenvolvimento da Educação Básica e de Valorização dos Profissionais da Educação (Fundeb), em 2007. Já a diversificação da oferta se materializa a partir dos anos finais da década de 2000, quando se explicitam formas de ampliação do ensino médio de tempo integral nas redes estaduais de ensino.

Fenômenos não coincidentes no tempo, o financiamento, a expansão e a diversidade da oferta de ensino médio representam um desafio à reflexão. Na expectativa de compreendê-los, a análise procura focalizá-los em suas especificidades, como também abordar suas interfaces.

Assim, o texto está dividido em quatro seções, além desta introdução. Na primeira seção, é apresentada a metodologia adotada para o estudo; na segunda, são analisadas as condições de financiamento da educação básica brasileira, desde a criação do Fundo de Manutenção e Desenvolvimento do Ensino Fundamental e de Valorização do Magistério (Fundef), compreendido como um instrumento indutor da expansão do ensino fundamental e com fortes repercussões no ensino médio e o Fundo de Manutenção e Desenvolvimento da Educação Básica e de Valorização dos Profissionais da Educação (Fundeb) como uma medida que equilibra a oferta; na terceira seção, é discutida a expansão do ensino médio como um fenômeno que remonta aos anos 1980, mas que adquire protagonismo na passagem do século XX para o XXI. A seção quatro aprofunda o estudo sobre o financiamento do ensino médio no Ceará, considerando, desde o movimento de municipalização do ensino fundamental no período pós-LDB até a diversificação da oferta iniciada em 2008, que continua pela década seguinte, considerando as condições de equidade no acesso e no tratamento dos alunos e, finalmente as considerações finais.

\section{Metodologia}

A metodologia adotada é de natureza explicativa, com uso de fontes de informações históricas, envolvendo dados quantitativos e documentos oficiais, bem como fontes secundárias de autores com produção sobre o assunto. Do ponto de vista quantitativo, trabalha com dados provenientes dos Censos Escolares coletados pelo Instituto Nacional de Estudos e Pesquisas 
Educacionais Anísio Teixeira (Inep), pelo Instituto Brasileiro de Geografia e Estatística (IBGE) e pelo Instituto de Pesquisa Econômica Aplicada (Ipea). No que se refere à abordagem qualitativa, procura analisar a relação da realidade com o objeto de estudo, possibilitando interpretações por parte do pesquisador, levando em conta contribuições advindas de outros estudos e outras pesquisas já realizados (DALFOVO; LANA; SILVEIRA, 2008).

A análise compreende o período 1980 - 2020, considerando o Brasil, a região Nordeste e o estado do Ceará, e se debruça sobre o ensino médio, a partir das matrículas, do financiamento dessa etapa da educação básica e da diversificação da oferta, fenômeno que vai começar a acontecer no fim da primeira década do século XX. Os dados de financiamento foram obtidos junto ao Sistema de Informações Orçamentária e Financeira do estado do Ceará, por meio de solicitação junto à Secretaria de Educação.

\section{Financiamento da educação}

A história da educação brasileira permite perceber diferentes momentos da política de financiamento. Segundo Vieira e Vidal (2015), esse processo pode ser divido em três fases. A primeira é caracterizada pela "indefinição de recursos", quando "os agentes e as fontes de recursos não são claramente identificados". Tal período tem início com a chegada dos jesuítas ao Brasil, prolongando-se até o início da década de trinta do século XX. A segunda se caracteriza pela presença de dispositivos constitucionais referentes à vinculação de recursos, fato sujeito a avanços e a recuos na legislação. A terceira fase se consolida a partir da sistemática da política de fundos, instituída a partir da criação do Fundef, em 1996, que tem continuidade com o Fundeb, em 2007.

Acatando tal periodização, é possível afirmar que, até a criação do Fundeb, os recursos para o ensino médio eram escassos no orçamento da educação. A compreensão dos impactos financeiros desses dois fundos contábeis sobre a educação é oportuna para a análise do tema proposto.

\subsection{O Fundef como instrumento indutor da expansão da oferta}

A criação do Fundef, em 1996, funciona como política indutora para a implementação, em maior ou menor intensidade, do que estabelece o art. 10 da LDB, de 1996, ao afirmar que

Os Estados incumbir-se-ão de: II - definir, com os Municípios, formas de colaboração na oferta do ensino fundamental, as quais devem assegurar a distribuição proporcional das responsabilidades, de acordo com a população a ser atendida e os recursos financeiros disponíveis em cada uma dessas esferas do Poder Público. 
A existência de um fundo contábil que equalizava o valor aluno-ano para todas as matrículas de ensino fundamental em cada estado da federação criou um ambiente favorável para que os municípios vislumbrassem uma oportunidade de receitas até então inexistentes ou precariamente asseguradas. Num primeiro momento, a ampliação de oferta de vagas nas redes municipais teve grande representatividade no processo de inclusão de novos alunos na escola e na universalização dessa etapa da educação básica. O segundo momento é marcado pela articulação política e pelas possibilidades de arranjos federativos do estado com seus municípios, definindo modelos sobre as "formas de colaboração" na oferta do ensino fundamental. Os estados optaram por processos distintos de municipalização, tais como: a) apenas dos anos iniciais do ensino fundamental; b) anos iniciais total e anos finais de modo parcial; c) anos iniciais e finais de modo parcial e d) anos iniciais e finais totais, caso do Ceará.

É oportuno compreender que, sendo constituído por fundos contábeis em cada um dos estados e no Distrito Federal, o Fundef expressa um custo-aluno muito diferenciado no território nacional. Este relaciona-se, de um lado, à capacidade financeira das unidades federadas e, de outro, à maior ou menor quantidade de matrículas no ensino fundamental nos respectivos estados e no Distrito Federal. Esse fenômeno pode ser compreendido através dos dados apresentados no Gráfico 1, que apresenta o valor aluno-ano por unidade da Federação no ano de 2006, último ano do Fundef.

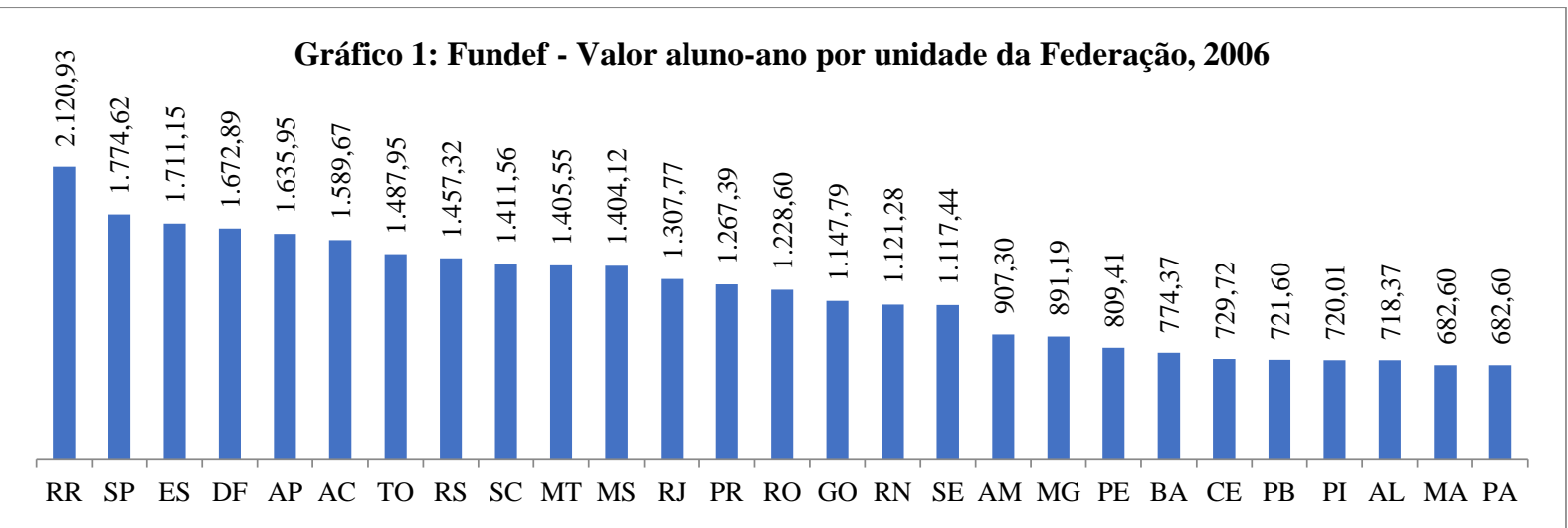

Fonte: FNDE, 2016.

O gráfico permite constatar uma expressiva disparidade no valor aluno-ano entre as unidades federadas, fato que foi comum durante toda a vigência do Fundef (1996 - 2006). Situações de desigualdade em que o valor aluno-ano de um estado chegava a ser o dobro ou o triplo do valor aluno-ano de outros estados da federação, como é possível observar os casos de Roraima, São Paulo e Espírito Santo num extremo e Pará, Maranhão e Alagoas no outro. Essa oscilação, como observado anteriormente, estava relacionada não apenas à capacidade 
financeira de cada ente federado, como também ao quantitativo de alunos matriculados no ensino fundamental. Assim, estados que passaram por grande expansão da oferta do ensino fundamental, em particular aqueles com menor capacidade de arrecadação, caso dos estados do Nordeste e do Pará, enfrentaram grandes desafios para fazer face à oferta de ensino fundamental e, mais ainda, de ensino médio, para o qual não havia reserva de recursos específicos.

Embora a Lei $\mathrm{n}^{\circ}$ 9424/1996 previsse, no art. 6º que "A União complementará os recursos do Fundo a que se refere o art. $1^{\circ}$ sempre que, no âmbito de cada Estado e do Distrito Federal, seu valor por aluno não alcançar o mínimo definido nacionalmente" isso não aconteceu durante a vigência do Fundef. Tal situação levou vários estados a ajuizarem ações contra o Governo Federal junto ao Supremo Tribunal Federal (STF) mediante o instrumento de Ação Direta de Inconstitucionalidade (ADI), reivindicando a complementação anunciada. A partir de 2015, resultados dos julgamentos deram ganho de causa a estados e municípios e estabeleceram a obrigação de a União pagar os valores a título de precatórios.

A criação do Fundef representa um marco na política de financiamento da educação básica no Brasil, e suas consequências foram observadas de forma imediata, com destaque para três aspectos: a) a equalização do valor-aluno ano do ensino fundamental da rede estadual e municipais por estado da federação; b) a universalização do ensino fundamental e c) a melhoria salarial dos docentes. Por outro lado, durante o período de vigência do Fundo, algumas questões emergiram como problemáticas, entre elas: a) a imediata pressão por vagas no ensino médio, sem que essa etapa contasse com algum tipo de complementação financeira e b) a manutenção das desigualdades interestaduais no valor aluno-ano. Esse tema será retomado adiante, ao se tratar das alternativas buscadas para o financiamento do ensino médio cearense. Se, em 2006, o Ceará contava com $\mathrm{R} \$ 729,72$ para o financiamento do ensino fundamental e escassos recursos para o financiamento do ensino médio, tal situação muda significativamente com a aprovação do Fundeb em 2007.

\subsection{O Fundeb como mecanismos de equilíbrio da oferta}

Demandas de um novo fundo que viesse substituir o Fundef existiram desde o início de sua criação. $\mathrm{O}$ esgotamento da capacidade financeira dos estados para fazer face às demandas pela expansão do ensino médio, por sua vez, tornaram a criação do Fundeb um imperativo de sobrevivência. Após período de significativos embates entre diferentes segmentos do setor público, protagonizados, sobretudo, pelos estados, através do Conselho Nacional de Secretários de Educação (Consed), da União Nacional dos Dirigentes Municipais de Educação (Undime) e 
das diversas organizações representativas de segmentos de educadores ligados à defesa do ensino público, o Fundeb foi aprovado pela Emenda Constitucional n ${ }^{0}$ 53, de 19 de dezembro de 2006, tendo sido regulamentado, pela Medida Provisória n 339, de 28 de dezembro do referido ano e entrando em vigor em $1^{0}$ de janeiro de 2007.

Tal como o Fundef, o Fundeb é constituído como um fundo contábil, existente em cada unidade da federação brasileira. Diferentemente do primeiro, porém, envolve recursos para alunos de toda a educação básica pública (creches, pré-escola, ensino fundamental, ensino médio, educação especial e educação de jovens e adultos). Seus recursos são distribuídos a municípios e a estados com base nas matrículas das respectivas redes.

Importante mencionar que, no caso do Fundeb, a contrapartida da União no financiamento da educação básica veio a representar importante mecanismo de equalização entre as diferentes instâncias federadas e sistemas de ensino, através de um custo-aluno anual que passou a orientar as políticas de financiamento da educação no país. Essa equalização se dá em torno de valor mínimo de referência, o que não significa um padrão nacional, uma vez que continuam existindo 27 fundos, um por estado, confirmando a persistência das desigualdades interestaduais, que poderiam ser equacionadas mediante a criação de um fundo único.

O Fundeb vai criar condições para expansão da oferta de educação infantil e ensino médio, ao assegurar recursos financeiros para estas duas etapas da educação básica. No caso do ensino médio, especialmente para os estados que optaram pela ampliação da municipalização do ensino fundamental, representa a condição de possibilidade da oferta dessa etapa sem depender exclusivamente de recursos do Tesouro Estadual.

O Gráfico 2 mostra a evolução do valor aluno-ano no país estabelecido pelo Fundeb evidenciando o significativo aumento do volume de recursos para a educação.

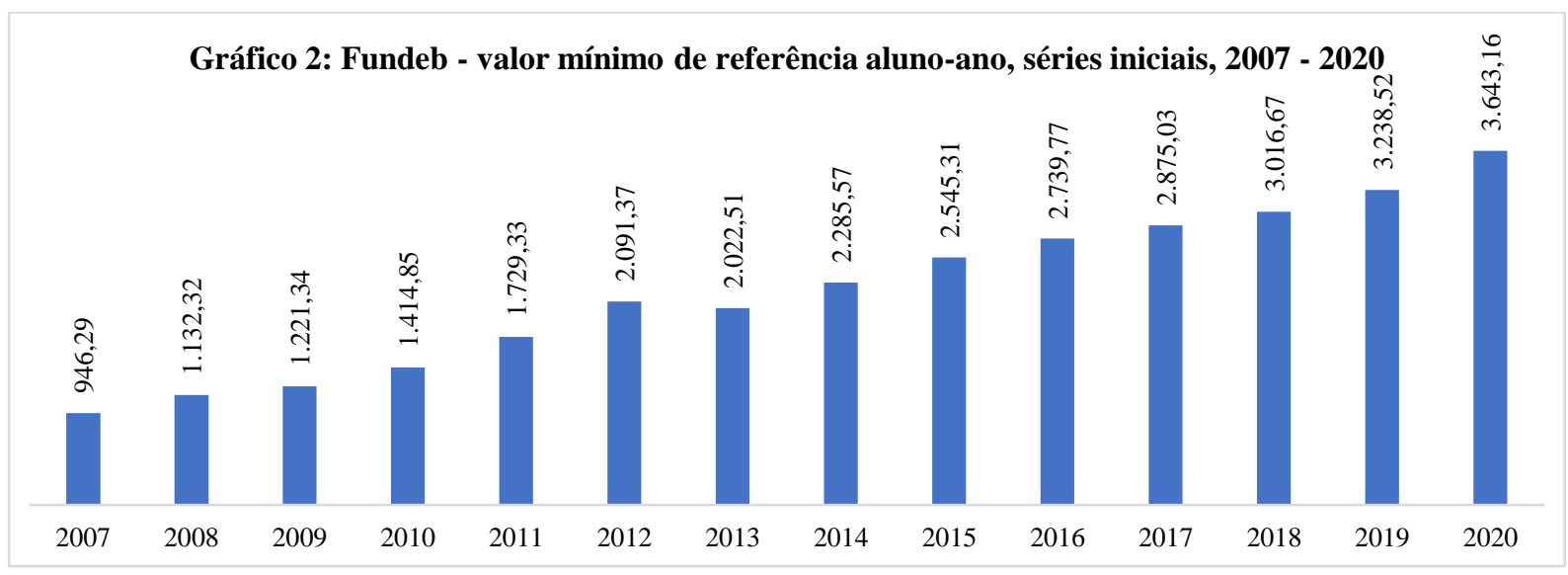

Fonte: Portarias Interministeriais, FNDE. 
Nesse gráfico se destacam dois aspectos importantes: o primeiro diz respeito à complementação da União, evidenciado no valor aluno-ano já em 2007, quando para alguns estados, representa $30 \%$ a mais do valor do aluno no último ano do Fundef, e o segundo, que o valor aluno-ano quadruplica nesses quatorze anos. Apesar dos avanços em relação ao fundo anterior (Fundef), o financiamento da educação via Fundeb começa a apontar esgotamento de sua capacidade financeira ao longo de sua vigência, e novos argumentos começam a orientar a criação de um novo fundo, desta feita, de forma definitiva, o que vem a acontecer com a Emenda Constitucional $n^{0}$ 108/2020.

Considerando os elementos desse cenário mais geral, é oportuno projetar o olhar sobre a expansão do ensino médio no Ceará, cuja análise permite evidenciar as dificuldades financeiras enfrentadas pelo estado desde a década de 1980, quando a pressão pelo aumento da oferta de vagas começa a se materializar. O próximo tópico procura analisar em detalhe esse processo, detendo-se sobre indicadores de crescimento.

\section{Expansão do ensino médio}

A nomenclatura "ensino médio", adotada na legislação do passado, é retomada pela Constituição de 1988 (Art. 208, II e pela Ementa Constitucional n ${ }^{0}$ 14/1996, Art. 211, §3º). Aparece em vários dispositivos da Lei de Diretrizes e Bases da Educação (nº 9394/96), de modo especial, quando define, em seu artigo art. 21, que "a educação escolar compõe-se de: I educação básica, formada pela educação infantil, ensino fundamental e ensino médio" e, no art. 35 , ao esclarecer que

\footnotetext{
O ensino médio, etapa final da educação básica, com duração mínima de três anos, terá como finalidades:

I - a consolidação e o aprofundamento dos conhecimentos adquiridos no ensino fundamental, possibilitando o prosseguimento de estudos;

II - a preparação básica para o trabalho e a cidadania do educando, para continuar aprendendo, de modo a ser capaz de se adaptar com flexibilidade a novas condições de ocupação ou aperfeiçoamento posteriores;

III - o aprimoramento do educando como pessoa humana, incluindo a formação ética e o desenvolvimento da autonomia intelectual e do pensamento crítico;

IV - a compreensão dos fundamentos científico-tecnológicos dos processos produtivos, relacionando a teoria com a prática, no ensino de cada disciplina.
}

A proposta do ensino médio como última etapa da educação básica, presente na LDB de 1996, procura avançar em relação à Lei $n^{0} 5692 / 71$, que altera a Lei $n^{\circ} 4024 / 61$, e fixa diretrizes e bases para o ensino de $1^{\circ}$ e $2^{\circ}$ graus, quando, no artigo art. $1^{\circ}$, inciso $1^{\circ}$, estabelece que "Para efeito do que dispõe os artigos 176 e 178 da Constituição [de 1946] entende-se por ensino primário a educação correspondente ao ensino de primeiro grau e por ensino médio, o 
de segundo grau”. Isso porque a LDB de 1961 definia, no art. 26, que “O ensino primário será ministrado, no mínimo, em quatro séries anuais" e, no art. 34, que "O ensino médio será ministrado em dois ciclos, o ginasial e o colegial, e abrangerá, entre outros, os cursos secundários, técnicos e de formação de professores para o ensino primário e pré-primário". Esses esclarecimentos são importantes para evitar análises equivocadas, especialmente quando se estuda períodos que compreendem as duas legislações.

A Tabela 1 mostra dados relativos a matrículas de $2^{\circ}$ grau/ensino médio no período 1980 -2020, correspondendo aos últimos quarenta anos para o país, a região Nordeste e o estado do Ceará. Os dados dos anos 1980 e 1990 se referem ao ensino de $2^{\circ}$ grau, em respeito à legislação então vigente.

Tabela 1 - Matrículas em $2^{\circ}$ grau/ensino médio, 1980 - 2020

\begin{tabular}{llllll}
\hline Brasil, região e UF & $\mathbf{1 9 8 0}$ & $\mathbf{1 9 9 1}$ & $\mathbf{2 0 0 0}$ & $\mathbf{2 0 1 0}$ & $\mathbf{2 0 2 0}$ \\
\hline Brasil & 2.823 .544 & 3.725 .133 & 8.192 .948 & 8.357 .675 & 7.550 .753 \\
Nordeste & 565.318 & 831009 & 1.923 .582 & 2.424 .793 & 2.130 .375 \\
Ceará & 85.190 & 104.053 & 264.431 & 411.109 & 362.470 \\
\hline
\end{tabular}

Fonte: IBGE e Censos Escolares, Inep.

Observando os dados relativos ao período analisado, constata-se que as matrículas do país crescem $167,4 \%$, a região Nordeste apresenta um aumento de $276,8 \%$, e o estado do Ceará de 325,5\%. Quando se analisa a situação por década, os maiores crescimentos ocorrem no período 1991 - 2000: 119,9\%, 131,5\% e 154,1, para o Brasil, Nordeste e Ceará, respectivamente. Outro aspecto a destacar é que, na década 2010 - 2020, inicia-se a redução de matrículas no país $(9,7 \%)$, na região Nordeste $(12,1 \%)$ e no estado do Ceará $(11,8 \%)$.

O Gráfico 3 permite visualizar a evolução de matrículas, em valores percentuais, para cada década nos três recortes territoriais.

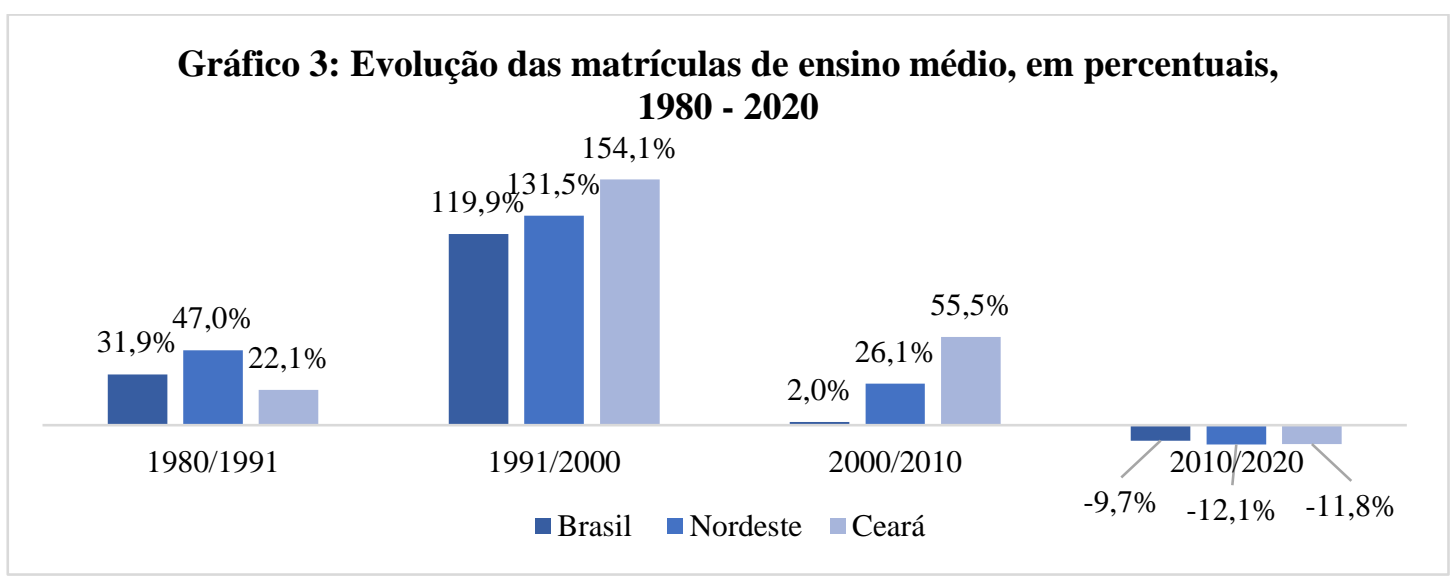

Fonte: IBGE e Sinopses Estatísticas da Educação Básica, Inep. 
O período de maior crescimento das matrículas de ensino médio é anterior à criação do Fundeb, numa década marcada pela responsabilidade legal dos estados na oferta dessa etapa da educação básica, estabelecida pela LDB. O crescimento da oferta descolado do financiamento implicou precarização das condições de acesso e de tratamento dos alunos, conduzindo a altas taxas de reprovação e de abandono, gerando problemas no fluxo escolar, aumentando a distorção idade-série e reduzindo os níveis de proficiência dos alunos nas avaliações em larga escala, a exemplo do Sistema de Avaliação da Educação Básica (Saeb). Quando se dá a criação do Fundeb, as matrículas do ensino médio já atingiram seus máximos e encontram-se em processo de estabilização ou queda em alguns estados.

No intuito de ampliar a análise sobre o acesso ao ensino médio, o Gráfico 4 apresenta dados sobre a evolução dos percentuais de frequência escolar para jovens de 15 a 17 anos no período 1980 - 2020. Importante destacar que, segundo a legislação vigente, essa faixa etária é considerada a ideal para o ensino médio, embora, no caso brasileiro, a persistência de taxas de reprovação e abandono tanto no ensino fundamental como no médio, deságue em jovens dessa faixa etária em distorção idade-série ou atraso escolar.

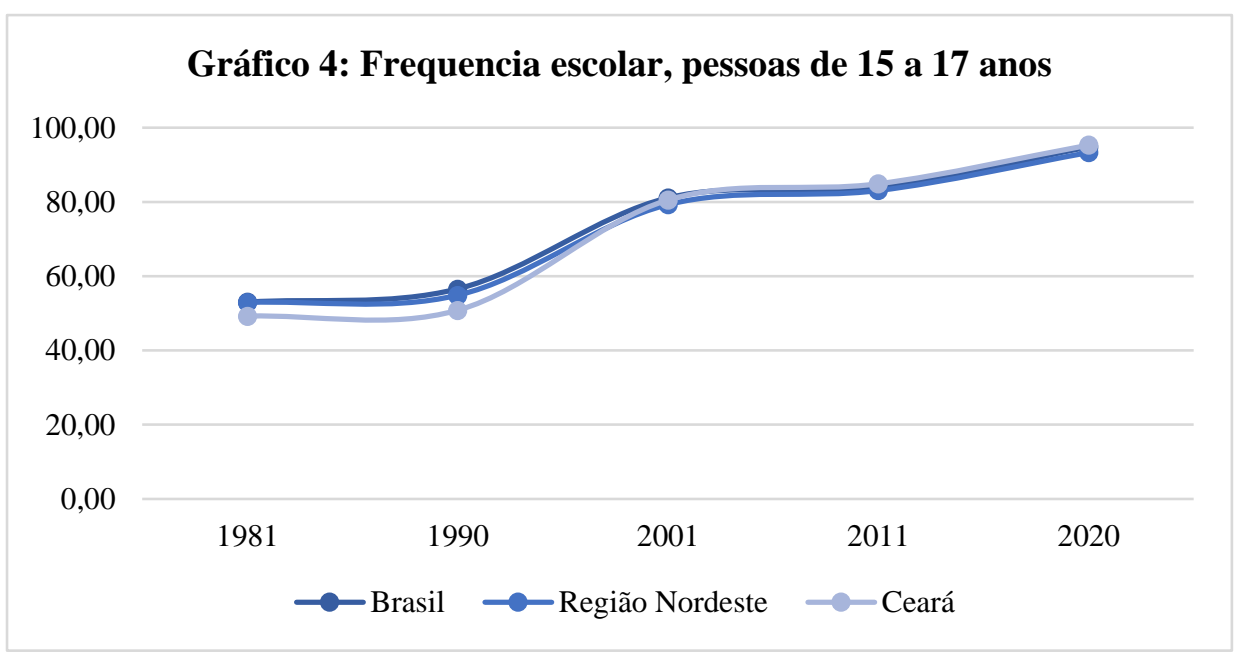

Fonte: http://www.ipeadata.gov.br/Default.aspx e Inep data.

Os dados mostram que os maiores crescimentos de frequência à escola por parte desses jovens se dão na década de 1990 - 2001, quando se atinge o patamar de $80 \%$ da população dessa faixa etária na escola tanto no Brasil, quanto no Nordeste e no Ceará. O aumento do acesso continua pelas décadas seguintes, chegando, em 2020, a mais de $93 \%$ em todos os recortes territoriais. No entanto, esses jovens não necessariamente estão cursando o ensino médio, como mostra o Gráfico 5. 


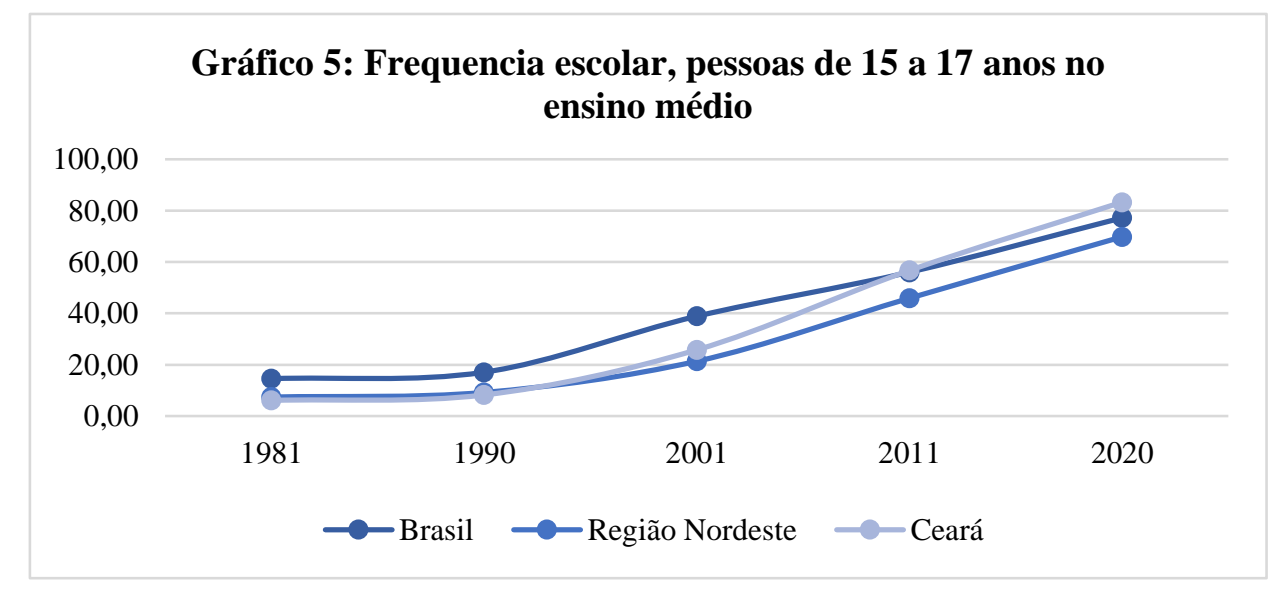

Fonte: http://www.ipeadata.gov.br/Default.aspx e Inep data

Os dados mostram que há um movimento no sentido da regularização do fluxo escolar, cujos maiores avanços ocorrem a partir dos anos 1990, continuando até os dias atuais. Embora o aumento percentual de jovens de 15 a 17 anos frequentando o ensino médio no período 1981 - 2020 seja de 429,8\% no Brasil, 843,6\% na região Nordeste e 1.265,4\% no estado do Ceará, ainda se registra uma parcela de jovens nessa faixa etária que não está matriculada no ensino médio, mesmo em 2020. Esse fato tem relação com a distorção idade-série decorrente de entrada tardia na escola e do histórico de reprovação e abandono durante o ensino fundamental e, mesmo, no ensino médio.

Visando lançar luzes sobre as matrículas de ensino médio da rede estadual cearense no período 1991 - 2020, o Gráfico 6 apresenta os dados por quinquênio.

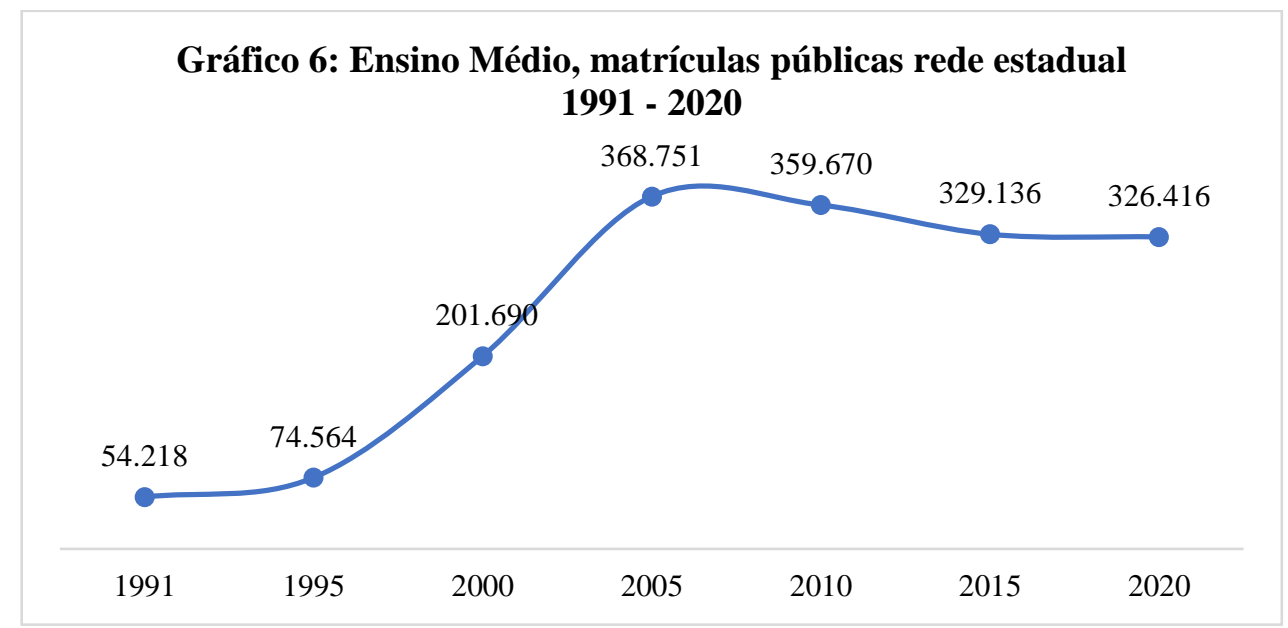

Fonte: Sinopses Estatísticas da Educação Básica, Inep.

A análise mostra que o crescimento mais significativo de matrículas de ensino médio na rede estadual ocorre no período 1995 - 2000 (170,5\%), sucedido pelo período 2000 - 2005 $(82,8 \%)$. A partir deste ano, inicia-se redução de matrículas, acumulando no período 2005 - 
2020, 11,5\%. Importante destacar que os maiores crescimentos nas matrículas de ensino médio no período ocorrem sob um contexto adverso do ponto de vista do financiamento, como se verá na seção a seguir.

\section{Financiamento e diversificação da oferta de ensino médio no Ceará}

Em tópicos anteriores, foram analisados aspectos relativos aos impactos financeiros do Fundef e do Fundeb no país, situando a expansão do ensino médio nesse contexto. Feitas essas considerações, passa-se a identificar as fontes alternativas buscadas pelo Ceará de modo a enfrentar sua incumbência para com essa etapa da educação básica e a emergência do fenômeno da redistribuição de matrículas.

\subsection{Fontes alternativas de financiamento ao ensino médio}

A opção do Ceará pela municipalização da oferta de ensino fundamental ${ }^{1}$ contribuiu $^{-}$ para que os recursos do Fundef fossem praticamente todos transferidos aos municípios. Tal situação levou o estado a enfrentar a falta de recursos próprios para fazer face ao vertiginoso crescimento das matrículas de ensino médio. Sem uma contrapartida em termos de novas fontes de recursos, o Ceará, como outros estados do Nordeste, precisou buscar recursos emergenciais junto à União para honrar compromissos básicos de custeio da máquina educacional. Esses recursos foram viabilizados por meio de programas e de projetos específicos, financiados com recursos da União ou de organismos internacionais, via empréstimos. De uma maneira geral, caracterizavam-se por definição a priori de como e onde deveriam ocorrer as despesas, aspecto que, na maioria das situações, engessava o já precário orçamento para o ensino médio. Datam desse período três iniciativas de apoio do governo federal aos estados: o Projeto Alvorada, o Programa de Melhoria e Expansão do Ensino Médio (Promed) e o Programa de Equalização das Oportunidades de Acesso à Educação Básica (Prodeb), vigentes entre os anos 2001 e 2006.

O Projeto Alvorada foi uma iniciativa do Governo Federal que contava com a parceria dos governos estaduais e municipais buscando criar as condições necessárias para reduzir a pobreza e as desigualdades regionais do país, tendo como ideia principal elevar a qualidade de vida da população e reduzir as desigualdades sociais. Participaram do projeto os estados do Acre, Alagoas, Bahia, Ceará, Maranhão, Pará, Paraíba, Pernambuco, Piauí, Rio Grande do Norte, Rondônia, Roraima, Sergipe e Tocantins e municípios dos demais estados com IDH

${ }^{1}$ Esse processo é analisado por Vieira e Vidal (2013) e Vieira; Plank e Vidal (2019) em artigos que tratam do regime de colaboração no referido estado. 
menor ou igual a 0,500, com ações nas áreas de: educação, voltadas ao ensino fundamental, ao ensino médio e à educação de jovens e adultos ${ }^{2}$. Embora os valores atribuídos a cada estado fossem expressivos, não permitia o pagamento de despesas de custeio, o maior problema enfrentado para o emergente crescimento do ensino médio.

O Programa de Melhoria e Expansão do Ensino Médio (Promed), conforme Resolução/CD/FNDE n 23, de 28 de maio de 2007, foi uma iniciativa desenvolvida pelo Fundo Nacional de Desenvolvimento da Educação (FNDE) que visava à celebração de convênios para assistência financeira às unidades da federação das regiões Norte e Nordeste, e teve como objetivo geral apoiar a promoção da reforma e expansão do ensino médio, melhorando a qualidade e o grau de cobertura dessa etapa da educação básica. O Programa de Equalização das Oportunidades de Acesso à Educação Básica (Prodeb) foi constituído por um fundo emergencial criado em 2004 pelo Governo Federal para apoiar o financiamento do ensino médio no Nordeste e no Pará. Em 2005, passou a abranger todos os estados brasileiros.

Os três programas citados, todos de caráter emergencial, embora representassem um apoio efetivo da União em colaborar para oferta de ensino médio, não representavam segurança financeira para os estados, pela descontinuidade de recursos, por exigências impostas nas categorias de despesas e pela falta de celeridade na prestação de contas para liberação de novas parcelas, gerando incertezas no planejamento das políticas para esse segmento da educação básica.

O financiamento do ensino médio passa a ter mais estabilidade quando a União começa a exercer sua função redistributiva de forma mais plena, e não mais em caráter pontual e emergencial. Isso só ocorreu sob a vigência de um novo governo, em 2007, e já com a criação do Fundeb. Com a implantação desse fundo, o estado passa a receber complementação da União e é capaz de orquestrar a melhoria da qualidade da oferta de ensino médio. Mesmo sob condições de melhoria do equilíbrio financeiro do ensino médio, o recurso à complementação da União sob a forma de projetos e de programas persiste como alternativa de financiamento ao ensino médio, como se verá a seguir.

O Governo Federal, por meio da Secretaria de Educação Profissional e Tecnológica (Setec), cria o programa Brasil Profissionalizado em 2007, que representa aporte financeiro adicional aos recursos do Fundeb e "possibilita a modernização e a expansão das redes públicas de ensino médio integradas à educação profissional, uma das metas do Plano de Desenvolvimento da Educação (PDE). O objetivo é integrar o conhecimento do ensino médio

\footnotetext{
${ }^{2}$ Fonte: http://www.mds.gov.br/relcrys/alvorada/apresentacao.htm\#1. Acesso em 07/01/2016
} 
à prática"’. É nesse espaço de novos aportes financeiros que o Ceará vai criar sua rede de escolas estaduais de educação profissional e iniciar o processo de diversificação da oferta nesta etapa da educação básica.

Por um longo período, desde a progressiva extinção da oferta de educação profissional resultante da reforma dos anos 1970, implementada pela Lei n ${ }^{\circ} 5692 / 71$, o Ceará ofertava apenas ensino médio regular de turno único nas escolas da rede estadual. Iniciativas de oferta de educação profissional eram responsabilidade da Secretaria de Ciência e Tecnologia (Secitece), que, ainda nos anos 1990, criou uma extensiva rede de Centros Vocacionais Tecnológicos (CVT) e Centros Tecnológicos (Centec) para responder por oferta de cursos técnicos de curta duração e de cursos técnicos de nível médio, visando qualificar a população em geral, incluindo egressos do ensino médio. Essa iniciativa funcionou de forma satisfatória, tendo servido, inclusive, de modelo para outras unidades da Federação, como Minas Gerais e Maranhão.

Com as alterações decorrentes do Decreto $n^{\circ} 5.154$ de 23/07/2004 que "regulamenta o $\S 2$ - do art. 36 e os arts. 39 a 41 da Lei n- 9.394, de 20 de dezembro de 1996, e da Lei $n^{\circ} 11.714$, de 16 de junho de 2008, que altera a Lei no 9.394, de 20 de dezembro de 1996, "para redimensionar, institucionalizar e integrar as ações da educação profissional técnica de nível médio, da educação de jovens e adultos e da educação profissional e tecnológica", a Secretaria de Educação Profissional e Tecnológica (Setec) do MEC concebe e estrutura o Programa Brasil Profissionalizado, uma iniciativa que repassa recursos do governo federal para que os estados invistam em suas escolas técnicas.

O Ceará foi um dos estados que buscaram esses recursos de modo a consolidar sua rede de escolas profissionais. Entre 2008 e 2020, o estado passa a contar com 122 escolas de ensino médio integrado à educação profissional, distribuídas em 98 municípios, onde estão matriculados 55.495 alunos, como mostra o Gráfico 7.

${ }^{3}$ http://portal.mec.gov.br/index.php?option= com_content $\&$ view $=$ article $\&$ id $=12325 \&$ Itemid $=663$ 


\section{Gráfico 7: Ensino Médio integrado à Educação Profissional, matrículas rede estadual 2008 - 2020}

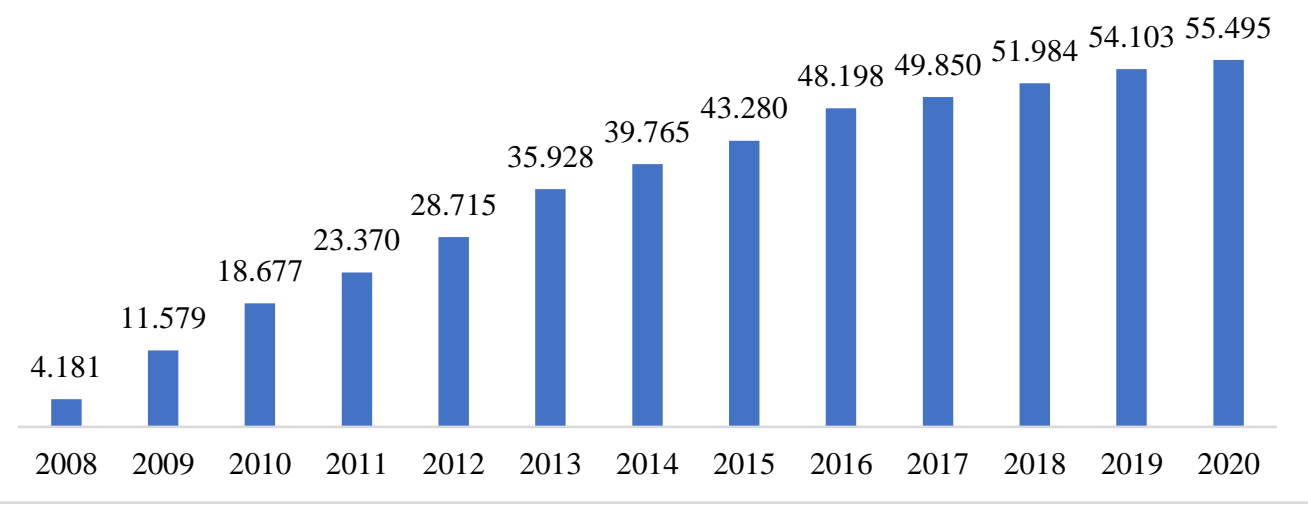

Fonte: Elaborado pelos autores a partir de dados dos Censos Escolares.

As escolas de ensino médio integrado à educação profissional funcionam em regime de tempo integral, com nove horas de aula diárias para os alunos, sendo um turno com oferta de ensino médio propedêutico e outro com formação profissional de nível técnico, três refeições e estágio supervisionado apoiado por bolsas para todos os alunos do $3^{\circ}$ ano dos cursos técnicos. Segundo Saldanha $(2014$, p. 31), essa modalidade de oferta de escola em tempo integral integrada, está "focada na oferta de melhores oportunidades de preparação para o trabalho, concebendo a escola de Ensino Médio como local privilegiado para a educação de nível técnico e de qualificação profissional”.

Com a emergência dessa nova modalidade, na rede estadual passam a coexistir dois tipos de oferta de ensino médio público: o ensino médio regular de turno único, ofertado nas escolas de ensino médio regulares com acesso amplo e irrestrito para todos os que possuem o ensino fundamental completo e a oferta de ensino médio integrado à educação profissional, oferecido em regime de tempo integral, que possui processos seletivos para admissão de alunos, com estabelecimento de critérios associados à meritocracia, como desempenho nas disciplinas de Língua Portuguesa e de Matemática durante os anos finais do ensino fundamental ou no $9^{\circ}$ ano, e não apresentar distorção idade-série.

Uma segunda iniciativa de diversificação da oferta de ensino médio se inicia em 2016, pela adesão, por parte da Secretaria de Educação (Seduc), ao Programa de Fomento às Escolas de Ensino Médio em Tempo Integral (EMTI) do Ministério da Educação (MEC), que transfere recursos financeiros através do FNDE para sua implantação (BRASIL, 2018). Esse modelo trabalha com disciplinas eletivas que valorizam os vários espaços e equipamentos disponíveis na unidade de ensino, direcionando o uso de laboratórios, sala de multimeios e demais espaços de convivência como ambientes de relevância para consolidar e oportunizar aprendizagens. A 
ideia norteadora é diversificar os percursos formativos dos alunos, dando-lhes oportunidades de se aproximar de outros saberes e conhecimentos para além do currículo escolar. No primeiro ano, a Seduc adapta 26 prédios escolares e, nos anos subsequentes, amplia esse quantitativo, atingindo 155 unidades em 2020. Essas escolas desenvolvem uma proposta curricular de tempo integral, atendendo alunos, que permanecem nove horas por dia na escola, têm direito a três refeições diárias e recebem 45 horas de aula por semana.

É oportuno observar que uma outra realidade dessa etapa da educação básica convive com as modalidades antes descritas: ensino médio regular de turno único (ER), ensino médio integrado à educação profissional (EEEP) e ensino médio em tempo integral (EEMTI). São as chamadas extensões de matrícula, também conhecidas como anexos escolares. A existência dessa oferta de ensino médio não é um fenômeno novo no Ceará. Sua origem remonta aos anos 2000, quando a conclusão do ensino fundamental por parte de muitos jovens começa a pressionar o poder público estadual por vagas no ensino médio. Para os jovens que concluíam o ensino fundamental nas escolas municipais localizadas nas comunidades e nos distritos, restava a alternativa de se deslocar, por meio de transporte escolar, para as escolas de ensino médio situadas na sede do município.

A criação de anexos escolares, vinculados a uma escola-sede localizada na zona urbana da cidade, representou uma solução para parcela dos egressos do ensino fundamental, que enfrentavam dificuldades como condições de acesso para o transporte escolar, pela ausência de estradas ou barreiras físicas como rios, passagens molhadas, serras etc., que impediam o uso de veículos em determinadas épocas do ano; elevado tempo de deslocamento para a escola estadual na sede do município, que, em algumas situações, consumia uma quantidade de horas superior ao tempo de um turno escolar; falta de condições para frequentar a escola durante o dia, por necessidade de ajudar os pais nas atividades do campo e a impossibilidade de frequentar a escola à noite devido à distância entre as localidades de residência desses jovens e a sede municipal, e questões político-sociais ligadas à valorização da identidade local, que cria dificuldades de aceitação de deslocamento para outras comunidades.

Ao longo desses vinte anos, a oferta de ensino médio público cearense convive com anexos escolares ou extensões de matrícula e, embora a Seduc, em suas diretrizes para os anos escolares de 2004, 2005 e $2006^{4}$, reconheça a existência dessa oferta e estabeleça orientações e procedimentos para sua criação, lotação de professores e condições de funcionamento, do ponto de vista de política pública, esse tema sempre foi tratado sem a devida atenção. Nos anos

\footnotetext{
${ }^{4}$ Não foi identificado um documento específico de regulamentação da oferta em extensões de matrícula, contudo, a oferta figura nas portarias de matrícula e lotação que orientam a organização da rede estadual, publicizadas anualmente em Diário Oficial do Estado (DOE).
} 
seguintes, esse assunto fica praticamente invisível do ponto de vista de diretrizes emanadas pelo sistema de ensino.

Nos anos de 2014 e 2015, pesquisadores do Grupo de Pesquisa Política Educacional, Gestão e Aprendizagem (GPPEGA) participam de uma pesquisa financiada pelo Centro de Estudos e Pesquisas em Educação, Cultura e Ação Comunitária (Cenpec) e pela Fundação Tide Setubal denominada Políticas para o ensino médio: o caso de quatro estados ${ }^{5}$, tendo como objetivo "descrever e analisar políticas implantadas por distintos estados brasileiros para o ensino médio, bem como o modo pelo qual as escolas situadas em territórios socialmente vulneráveis respondem aos desafios e às possibilidades colocados por essas políticas" (BATISTA et al., 2016, p. 6).

É no contexto da referida investigação que a questão das extensões de matrícula na rede estadual do Ceará ganha materialidade. Os dados fornecidos pela Seduc mostravam que “[...] em 2015 existiam 402 anexos vinculados a 173 escolas de ensino médio regular, e neles estavam matriculados 34.787 alunos" (VIEIRA et al., 2017, p. 56). Os achados da pesquisa evidenciaram que o Estado vem atendendo à demanda de ensino médio a partir de condições de oferta muito desiguais, estando, num extremo, as escolas de ensino médio integrado à educação profissional que possuem condições de infraestrutura, serviços educacionais e corpo docente com alto padrão de qualificação e, no outro extremo, as extensões de matrícula, que funcionam em prédios com precária infraestrutura, em que os alunos têm menos de 4 horas-aula por dia e um corpo docente com parcos recursos pedagógicos, além de desenvolverem uma docência polivalente.

O caso das extensões de matrícula é analisado por Lima (2020), que denominou essa modalidade de oferta como "escolas invisíveis". De fato, embora seus professores e seus alunos frequentem um prédio diferente das escolas que abrigam suas matrículas e sejam responsáveis por sua gestão, na perspectiva do Censo Escolar e do público externo, estas não existem. São conhecidas apenas pelas escolas-sede encarregadas de sua administração e por aqueles que, por razões diversas, têm suas condições de ensino-aprendizagem empobrecidas pelas limitações apresentadas por tais unidades.

Ao associar os temas expansão de matrículas, financiamento e diversificação da oferta no estado do Ceará, o que se observa é um expressivo descompasso entre os dois primeiros e, uma vez dada as condições financeiras, a criação de iniquidades no acesso e na permanência dos alunos nas escolas, com reflexos no sucesso escolar. É o que será analisado na próxima 
subseção.

\subsection{Diversificação e equalização da oferta de ensino médio}

Visando a aprofundar a análise sobre a diversificação da oferta de ensino médio e o financiamento dessa etapa da educação básica no Ceará, procurou-se investigar o comportamento das matrículas no período 2016 - 2020, uma vez que a iniciativa de criação das escolas em tempo integral (EEMTI) começam no referido ano. A Tabela 2 apresenta os dados de matrícula de cada uma das ofertas no período considerado.

Tabela 2 - Matrículas de ensino médio por tipo de oferta, rede estadual do Ceará

\begin{tabular}{llllll}
\hline Tipo de oferta & $\mathbf{2 0 1 6}$ & $\mathbf{2 0 1 7}$ & $\mathbf{2 0 1 8}$ & $\mathbf{2 0 1 9}$ & $\mathbf{2 0 2 0}$ \\
\hline Ensino Médio Regular & 262.440 & 228.135 & 209.783 & 182.103 & 187.447 \\
Ensino Médio Integrado à Educação Profissional & 48.089 & 49.894 & 52.010 & 54.058 & 55.431 \\
Ensino Médio em Tempo Integral & 8.750 & 29.925 & 44.357 & 59.649 & 57.144 \\
Anexo Escolar & 19.005 & 21.582 & 23.128 & 27.284 & 26.262 \\
Total & $\mathbf{3 3 8 . 2 8 4}$ & $\mathbf{3 2 9 . 5 3 6}$ & $\mathbf{3 2 9 . 2 7 8}$ & $\mathbf{3 2 3 . 0 9 4}$ & $\mathbf{3 2 6 . 2 8 4}$ \\
\hline
\end{tabular}

Fonte: Secretaria de Educação do estado do Ceará, 2021

Os dados referentes aos últimos cinco anos mostram que as matrículas nas escolas regulares de turno único reduzem 28,6\%; nas escolas de ensino médio integrado à educação profissional, crescem 15,3\%; nas escolas de ensino médio de tempo integral aumentam 553,1\% e, nas extensões de matrículas, crescem 38,2\%. Também é possível observar que, nos últimos cinco anos, a rede estadual de ensino médio amplia a oferta de matrículas em tempo integral, passando de 16,8\% em 2016 para 34,5\% em 2020. O Gráfico 8 permite observar a evolução de cada tipo de oferta.

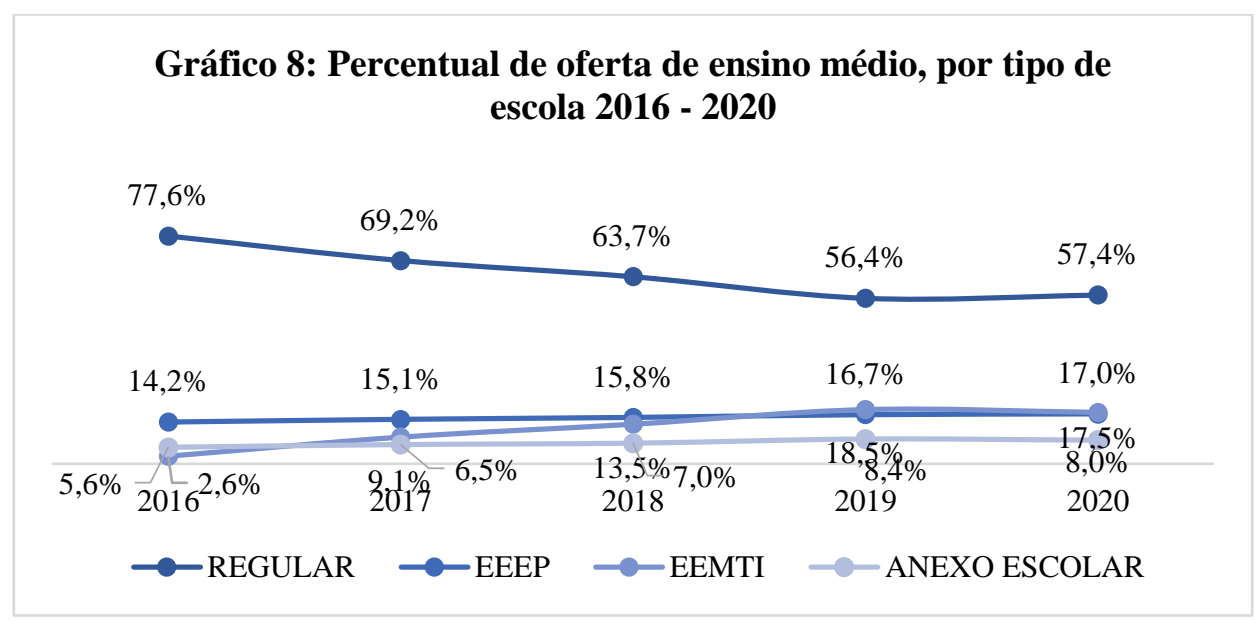

Fonte: Elaborado pelas autoras a partir de dados dos Censos Escolares 
Considerando os quatro tipos de oferta, é previsível que os investimentos destinados a cada uma delas seja diferente, a considerar as condições de infraestrutura e de atendimento aos alunos. Para aprofundar a análise, procurou-se fazer um estudo do valor aluno-ano por tipo de oferta em 2019, momento que antecede a pandemia da Covid-19. Para tanto, foi solicitada, à Secretaria de Educação, a execução orçamentária e as matrículas do ensino médio, por tipo de oferta, relativa ao ano de 2019, como mostra a Tabela 3.

Tabela 3 - Execução financeira de 2019, por tipo de oferta de ensino médio

\begin{tabular}{llll}
\hline Tipo de oferta & Total executado & Matrículas 2019 & Valor aluno-ano \\
\hline EEMTI & $266.571 .399,69$ & 31.595 & $8.437,14$ \\
EEEP & $569.256 .846,26$ & 54.058 & $10.530,48$ \\
ER & $1.874 .585 .088,07$ & 237.441 & $7.894,95$ \\
Total & $\mathbf{2 . 7 1 0 . 4 1 3 . 3 3 4 , 0 2}$ & $\mathbf{3 2 3 . 0 9 4}$ & $\mathbf{8 . 3 8 8 , 9 3}$ \\
\hline
\end{tabular}

Fonte: Siof - Sistema Integrado Orçamentário e Financeiro e Censo Escolar/INEP

Pesquisa realizada dia 02/07/2021 no site: http://web3.seplag.ce.gov.br/siofconsulta/Paginas/frm_consulta_execucao.aspx

Segundo o Sistema Integrado Orçamentário e Financeiro (SIOF) do estado, existem três categorias de escolas estaduais: a) Tempo Integral (EEMTI); b) Educação Profissional (EEEP) e c) Ensino Médio Regular (ER). Nas ER estão incluídas as matrículas das extensões de matrículas, motivo pelo qual não é possível identificar um valor aluno-ano para essa oferta. Embora, burocraticamente, seja possível pressupor que os custos de umas e de outras possa ser calculado como semelhante na prática, os gastos com essas unidades são significativamente inferiores. Como mostra o estudo de Lima (2020, p. 273), a precariedade das instalações e das condições de trabalho nessas unidades escolares, gera uma contradição: “embora proporcionem o ingresso ao ensino médio, acabam por deslocar as desigualdades educacionais da dimensão de oportunidade de acesso para a de condições de tratamento, promovendo assim, 'iniquidades' de oferta no interior da rede estadual de ensino" ao mesmo tempo em que representam uma "oferta invisível".

O maior valor aluno-ano é destinado às EEEP, sendo 33,3\% superior ao valor aluno-ano das ER, sucedido pelo valor aluno-ano das EEMTI, que é 7\% superior ao valor aluno-ano das ER. Sobre os alunos que frequentam as extensões de matrículas, considerando as precárias condições de oferta, inclusive do corpo docente, em que prevalecem professores temporários e polivalentes, estima-se que o valor aluno-ano é inferior aos das ER. Tais dados confirmam o que foi previsto na discussão teórica e mostram que, embora o direito subjetivo à educação seja garantido, ele o é em condições de tratamento muito distintas, conduzindo a iniquidades no interior do sistema estadual de ensino. A inexistência de uma execução orçamentária específica 
para uma oferta escolar que representa entre 5 a $8 \%$ das matrículas de ensino médio da rede estadual aponta para a ausência de iniciativas de política educacional dirigidas para esses jovens, que podem ser identificados como os mais vulneráveis entre todos.

\title{
Considerações finais
}

A configuração de políticas nem sempre obedece a uma lógica em que a formulação precede a implementação. Há várias razões teóricas e práticas para tanto que escapa à presente análise aprofundar. Certo é que no mundo real

\begin{abstract}
A elaboração de políticas não ocorre em estágios distintos. Os 'estágios' de políticas não apenas se confundem, como muitas vezes são inseparáveis. No mundo real, problemas e soluções de política emergem juntos, mais do que uns antes e outros depois. Noutras palavras, planos podem ser apresentados simultaneamente ou mesmo antes da identificação de uma necessidade de ação (HALLSWORTH, PARKER \& RUTTER, 2011, p. 6 - Tradução dos autores)
\end{abstract}

Ao aprofundar a reflexão sobre o financiamento, a expansão e a diversificação da oferta de ensino médio no Ceará, é possível confirmar a procedência dos argumentos em torno do caráter, por vezes, inseparável "dos problemas e soluções de políticas”. Ao mesmo tempo, permite formular algumas considerações. Em primeiro lugar, a trajetória das políticas examinadas neste artigo permite supor que a expansão do ensino médio nos moldes em que tal processo ocorreu não foi planejada. Ao que tudo indica, o estado respondeu à demanda por oferta de vagas do ensino médio, mesmo sem condições financeiras adequadas para tanto. Nesse sentido, o crescimento sob condições financeiras extremamente adversas contribuiu para a adoção de estratégias de sobrevivência que, não raro, resultaram em improvisos. O surgimento das extensões de matrículas, por exemplo, situa-se nesta zona de sombra, em que a necessidade de aumentar o número de vagas, levou à adoção de soluções precárias, afastando-se de padrões mínimos de qualidade e da oferta de um ensino comum a todos.

O recurso a iniciativas externas como mecanismo de obtenção de aportes financeiros para o ensino médio, por sua vez, veio a imprimir novos rumos para esta etapa de escolaridade. A adesão a iniciativas de apoio financeiro do governo federal a estados em maiores dificuldades, em período anterior à aprovação de um fundo de subvinculação de recursos para toda a educação básica, levou o estado a aderir a iniciativas como o Projeto Alvorada, o Promed e o Prodeb, vigentes entre os anos 2001 e 2006.

Em um segundo momento, mesmo em período de maior estabilidade financeira, a adesão a iniciativas financiadas pelo governo federal veio a ressignificar a oferta até então existente. Esse foi o caso da expansão do ensino médio integrado à educação profissional a 
partir de 2008 e do ensino médio integral, desde 2016. Ambos os programas tiveram impacto significativo sobre a diversificação, que passou a pautar a oferta de ensino médio. $\mathrm{O}$ crescimento das extensões de matrículas sob um contexto financeiro mais favorável do ponto de vista do financiamento, por sua vez, revela a existência de desafios muito maiores na oferta de ensino do que indicam as aparências.

É perceptível que o conjunto de iniciativas relacionadas à expansão do ensino médio terminou por criar quatro tipos de ofertas escolares no interior da rede estadual, que, embora convivam em relativa harmonia, revelam situações de iniquidades agudas. O financiamento ou a sua ausência pode ter contribuído para o crescimento de tais desigualdades.

\section{Referências}

BATISTA. A. A. G. et al. Políticas para o Ensino Médio e desigualdades escolares e sociais: os casos do Ceará e de Goiás, Pernambuco e São Paulo. Cadernos Cenpec, São Paulo, v.6, n. $2,2016$.

BRASIL. Constituição da República Federativa do Brasil de 1988. Disponível em: http://www.planalto.gov.br/ccivil_03/constituicao/constituicao.htm. Acesso em: 25 jun. 2021.

BRASIL. Decreto $n^{\circ} 5.154$ de 23/07/2004. Disponível em: http://www.planalto.gov.br/ccivil_03/_ato2004-2006/2004/decreto/d5154.htm. Acesso em: 30 jun. 2021.

BRASIL. Emenda Constitucional $n^{\circ}$ 59/2009. Disponível em: http://www.planalto.gov.br/ccivil_03/constituicao/emendas/emc/emc59.htm. Acesso em: 30 jun. 2021.

BRASIL. Emenda Constitucional no 53, de 19 de dezembro de 2006. Disponível em: http://www.planalto.gov.br/ccivil_03/constituicao/emendas/emc/emc53.htm. Acesso em: 25 jul. 2021.

BRASIL. Emenda Constitucional no 108 de 26 de agosto de 2020. Disponível em: http://www.planalto.gov.br/ccivil_03/constituicao/emendas/emc/emc108.htm. Acesso em 22 jul. 2021.

BRASIL. Emenda Constitucional $n^{\circ}$ 14, de 12 de setembro de 1996. Disponível em: http://www.planalto.gov.br/ccivil_03/constituicao/emendas/emc/emc14.htm. Acesso em: 29 jul. 2021.

BRASIL. Lei $n^{o} 11.714$ de 16 de junho de 2008. Disponível em: http://www.planalto.gov.br/ccivil_03/_ato2007-2010/2008/lei/111741.htm. Acesso em: 30 jun. 2021

BRASIL. Lei $n^{\circ} 4.024$ de 20 de dezembro de 1961. Disponível em: http://www.planalto.gov.br/ccivil_03/leis/14024.htm. Acesso em 28 jun. 2021. 
BRASIL. Lei $n^{\circ}$ 9.424, de 24 de dezembro de 1996. Disponível em: http://www.planalto.gov.br/ccivil_03/leis/19424.htm. Acesso em: 3 jul. 2021.

BRASIL. Lei $n^{\circ} 9394$ de 20 de dezembro de 1996. Disponível em: http://www.planalto.gov.br/ccivil_03/leis/ 19394.htm. Acesso em: 30 jun. 2021.

BRASIL. Lei $n^{\circ}$ 5.692, de 11 de agosto de 1971. Disponível em: http://www.planalto.gov.br/ccivil_03/leis/15692.htm. Acesso em 13 jun. 2021.

BRASIL. Manual de Execução Financeira do programa de Fomento às escolas de Ensino Médio em Tempo Integral. 2018. Disponível: file://home/joizia/Downloads/ resolucao_n16_0 7122017_anexo02_manual_execucao_financeira_emti.pdf. Acesso em:

BRASIL. Medida Provisória nº 339, de 28 de dezembro 2006. Disponível em: http://www.planalto.gov.br/ccivil_03/_ato2004-2006/2006/mpv/339.htm. Acesso em: 24 jul. 2021.

DALFOVO, Michael Samir; LANA, Rogério Adilson; SILVEIRA, Amélia. Métodos quantitativos e qualitativos: um resgate teórico. Revista Interdisciplinar Científica Aplicada, Blumenau, v.2, n.4, p.01-13, Sem II. 2008.

FNDE. Resolução/CD/FNDE $n^{\circ} 23$, de 28 de maio de 2007. Disponível em: https://www.fnde.gov.br/index.php/acesso-a-informacao/institucional/legislacao/item/3144resolu\%C3\%A7\%C3\%A3o-cd-fnde-n\%C2\%BA-23-de-28-de-maio-de-2007. Acesso em 29 jun. 2021.

HALLSWORTH, PARKER \& RUTTER. Policy Making in the Real World: Evidence and Analysis. Institute for Government, UK, 2011.

LIMA, Ana Léa Bastos. Escolas invisíveis: as extensões de matrícula de ensino médio da rede estadual de ensino do Ceará. Tese de Doutorado. Universidade Estadual do Ceará. Programa de Pós-Graduação em Educação. Fortaleza, 2020. Disponível em: http://www.uece.br/ppge/wp-content/uploads/sites/29/2020/08/Tese_ANA-LEA-BASTOSLIMA.pdf. Acesso em: 28 jul. 2021.

SALDANHA, A. D. de F. Gestão financeira da política de ensino médio integrado e integral do Ceará. Dissertação Mestrado Profissional CAEd/FACED/UFJF. Juiz de Fora, julho de 2014.

VIEIRA, Sofia Lerche et al. Reações das políticas educacionais estaduais nas escolas: um estudo de caso em escolas do Ceará, Goiás, Pernambuco e São Paulo. Cadernos Cenpec Nova série, v. 6, n. 2, 2017.

VIEIRA, Sofia Lerche; PLANK, David Nathan; VIDAL, Eloisa Maia. Política Educacional no Ceará: processos estratégicos. Educação \& Realidade, v. 44, 2019.

VIEIRA, Sofia Lerche; VIDAL, Eloísa Maia. Construindo uma história de colaboração na educação: a experiência do Ceará. Educação \& Sociedade, v. 34, p. 1075-1093, 2013.

VIEIRA, Sofia Lerche; VIDAL, Eloisa Maia. Política de financiamento da educação no 
Brasil: uma (re) construção histórica. Em Aberto, v. 28, n. 93, 2015. 